Educación para la autonomía: inventarios de la memoria en el contexto del giro a la ultraderecha en Brasil

Education for Autonomy: Inventories of Memory in the Context of the Turn to the Extreme Right in Brazil

Éducation pour l'autonomie: inventaires de la mémoire dans le contexte du virage à l'extrême droite au Brésil

\title{
Menara Guizardi
}

\section{OpenEdition}

\section{Journals}

Edición electrónica

URL: http://journals.openedition.org/rccs/10414

DOI: $10.4000 /$ rccs. 10414

ISSN: 2182-7435

Editor

Centro de Estudos Sociais da Universidade de Coimbra

Edición impresa

Fecha de publicación: 1 mayo 2020

Paginación: 147-168

ISSN: 0254-1106

Referencia electrónica

Menara Guizardi, «Educación para la autonomía: inventarios de la memoria en el contexto del giro a la ultraderecha en Brasil », Revista Crítica de Ciências Sociais [En línea], 121 | 2020, Publicado el 15 abril 2020, consultado el 17 abril 2020. URL : http://journals.openedition.org/rccs/10414 ; DOI : https:// doi.org/10.4000/rccs. 10414

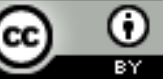




\title{
MENARA GUIZARDI
}

\section{Educación para la autonomía: inventarios de la memoria en el contexto del giro a la ultraderecha en Brasil}

\begin{abstract}
Este artículo aborda la confluencia entre la educación y la política reflexionando sobre el papel de la memoria social en Brasil, donde la ultraderecha avanza con el apoyo de los votantes que se adhieren a discursos del odio. Primero realizaré un debate teórico sobre la relación que existe entre política, memoria y educación, enmarcando así las categorías que guían las reflexiones desarrolladas a lo largo del texto. En segundo lugar, narraré mi experiencia etnográfica en las elecciones presidenciales brasileñas del 2018 y de diálogo con Carlos, un joven negro de la ciudad brasileña de Foz de Iguazú, destinatario de las ayudas educacionales del gobierno del Partido de los Trabajadores y votante de Jair Bolsonaro. En las consideraciones finales identificaré el papel que desempeñan la memoria social y los "inventarios de la memoria" como herramientas para superar, desde la educación, la forclusión política de los sujetos.
\end{abstract}

Palabras-clave: autonomía; Brasil; desigualdad social; educación; memoria; ultraderecha (política).

Palavras-chave: autonomia; Brasil; desigualdade social; educação; extrema-direita (política); memória.

\section{Introducción}

El presente artículo aborda la confluencia entre la educación y la política reflexionando sobre el papel de la educación en Brasil, donde la ultraderecha avanza con el apoyo de los votantes que, cada vez con más fuerza, piden a los gobiernos medidas y acciones basadas en el principio de la violencia, haciendo una lectura de las relaciones humanas atravesada por el odio hacia quienes son considerados como "los otros" (Aquino, 2019; Casimiro, 2018; Ezequiel et al., 2019; Girelli, 2019; Müller, 2019; Neves, 2018; Solano, 2019). Aquí desarrollo las reflexiones suscitadas a partir de mis investigaciones en la Triple Frontera del Paraná (entre Argentina, Brasil y Paraguay).

Esta región fronteriza situada en el sistema fluvial de los ríos Iguazú y Paraná, registra el mayor flujo humano, turístico, de mercancías y de 
actividades ilícitas de toda Sudamérica (Cardin, 2012: 208). Su ámbito territorial está formado por la conurbación de tres ciudades que, sumadas, contabilizan más de 600 mil personas (Renoldi, 2014: 2): Foz de Iguazú (en el lado brasileño), Ciudad del Este (en el lado paraguayo) y Puerto Iguazú (en el lado argentino).

Desde el 2016, vengo investigando las migraciones y los desplazamientos femeninos en este territorio fronterizo a través de una metodología antropológica etnográfica. La etnografía consiste en la observación sistemática de los contextos sociales con la finalidad de participar en ellos y simultáneamente registrarlos (en diarios de campo), analizarlos y construir relatos interpretativos. Además, la perspectiva metodológica etnográfica busca la interacción crítica entre los sujetos de estudio y los investigadores. Por la misma razón, se trata de un enfoque, un método y un ejercicio de relato de carácter intersubjetivo (Guber, 2001: 12). El enfoque etnográfico utilizado en mis incursiones en la Triple Frontera siguió las delimitaciones particulares del Extended Case Method (ECM) [Metodología del Caso Extendido], desarrollado por Max Gluckman en el marco de la Escuela de Manchester (Frankenberg, 2006). ${ }^{1}$

En octubre del 2018 viajé a la frontera hospedándome en el lado brasileño, en Foz de Iguazú, para realizar trabajo de campo durante tres semanas. La ciudad está ubicada en el estado de Paraná, cuya demografía se caracteriza por un elevado porcentaje de migrantes (y descendientes de migrantes) italianos y alemanes. Asimismo, desde los años 1980 la ciudad ha recibido las migraciones internas de trabajadores rurales afrobrasileños procedentes de las regiones del centro-oeste y nordeste de Brasil, que se asentaron en el lado paraguayo de la frontera -de donde fueron expulsados en la primera década del siglo XXI, debido a las apropiaciones de tierras llevadas a cabo por grandes latifundistas brasileños productores de soja (Fogel, 2008).

La intensificación de la migración europea en esta región limítrofe -entre la segunda mitad del siglo XIX y la primera del XX- reordenó las fronteras identitarias y morales entre los distintos grupos que la habitan (Giménez Béliveau, 2014). La ocupación de las tierras fronterizas por parte de los europeos estuvo acompañada por una narrativa particular, pautada en la

\footnotetext{
${ }^{1}$ El ECM implica al menos tres aspectos que lo diferencian de los abordajes etnográficos considerados clásicos: primero, en vez de recortar de forma descontextualizada los ejemplos etnográficos usándolos para reforzar concepciones generales preestablecidas, se propone narrar las experiencias en el terreno en su secuencialidad, acompañando el desarrollo de la escena o jornada (Burawoy, 1998: 5); segundo, se desarrolla a partir del estudio de interacciones sociales con potencial conflictivo (Gluckman, 2006: 17); y tercero, con el objetivo de comprender diacrónicamente las situaciones sociales observadas, presupone identificar procesos históricos que inciden en la experiencia cotidiana (Mitchell, 2006: 29).
} 
valorización del esfuerzo y del trabajo de los primeros colonos: aquello que Giménez Béliveau (ibidem: 212) identifica como la defensa y el enaltecimiento de "la cultura del trabajo" de dichos migrantes. Este marco axiomático conformó una distinción jerárquica: una formulación retórica de la superioridad moral y civilizatoria de estos colonos, sus hijos y nietos sobre los afrobrasileños, los paraguayos y los indígenas. Este discurso, con claros tintes racistas, sirvió para justificar la apropiación de las tierras por parte de estos europeos y sus descendientes. Estas mismas ideas y valores siguen vigentes en la actualidad.

Pero en aquel viaje me apercibí de un escenario particular que se estaba articulando en Foz de Iguazú. Nos encontrábamos en la primera vuelta de las elecciones presidenciales brasileñas y la ciudad estaba atravesada por una profusión de discursos del odio que me resultaron completamente acuciantes. En las siguientes páginas abordo cómo la asunción de estos discursos por parte de un joven afrobrasileño condujo a una serie de reflexiones intersubjetivas sobre el papel que debería desempeñar la educación en la producción de una memoria social que incorpore las diferentes experiencias de los sujetos y los grupos sociales.

El texto estará dividido en tres partes. Primero realizaré un debate teórico sobre la relación entre la política, la memoria y la educación, enmarcando las categorías que guían mis reflexiones. En segundo lugar, narraré mi experiencia etnográfica en Foz durante las elecciones presidenciales brasileñas del 2018 y el diálogo con Carlos, un joven negro destinatario de las políticas educacionales del gobierno del Partido de los Trabajadores y votante de Jair Bolsonaro. En las consideraciones finales propondré los "inventarios de la memoria" como herramienta para superar, desde la educación, la forclusión política de los sujetos. ${ }^{2}$

\section{Política, memoria y educación}

Las tres categorías que dan título a la presente sección constituyen los ejes analíticos de este texto. Se tratan de conceptos polisémicos, que articulan campos de debates cuya síntesis excede a los límites de un artículo. Lo anterior no me excusa, no obstante, de ofrecer mis posicionamientos sobre estos tres términos, tarea a la que me dedico en esta sección. Las definiciones que

\footnotetext{
${ }^{2}$ La forclusión constituye un concepto lacaniano que alude a la construcción de la personalidad. En particular, se refiere al proceso traumático a partir del cual los sujetos sufren la no inscripción simbólica de un significante fundamental (Lacan hace referencia a la no inscripción de la ley paterna). La definición del concepto y sus usos analíticos en las ciencias sociales, especialmente en lo que concierne a la jerarquización simbólica del racismo en Brasil, se explicará en los apartados subsiguientes.
} 
aquí aporto constituyen una elección situacional: apuntan, como se verá más adelante, a mi propia percepción política -intersubjetiva- sobre mi posición con relación a estos debates. ${ }^{3}$

Hace un siglo, Max Weber pronunciaba sus clásicas conferencias que impactarían sobremanera la discusión posterior de la definición sociológica de la política (Portantiero, 1982: 431). Previniendo a los asistentes de que su debate decepcionaría a muchos, Weber (1992 [1919]) manifiesta que una definición analítica de la política no podría volcarse en los contenidos de las actividades consideradas en este ámbito, ni tampoco en las reflexiones sobre aquello que estas actividades debieran ser. Así, avanza hacia una categorización de la política en cuanto a lo que ella es: como práctica histórica, como un conjunto de articulaciones, relaciones y disposiciones que se dotan de sentido en cierto momento histórico. En estas reflexiones estipula que la política está prototípicamente establecida a partir de una acción racional con relación a finalidades (como se refleja en la máxima maquiavélica "los fines justifican los medios"); que esta engendra la disputa por el dominio del poder de decisión sobre las personas, los recursos y los simbolismos. Por consiguiente, la política es un ejercicio de dominación que busca construir una relación de poder legítima. Afirma que esta legitimidad es vehiculizada por el Estado y descansa en la potestad de violencia que el aparato estatal despliega o puede, potencialmente, desplegar. Así, el Estado sería "una relación de dominación de hombres sobre hombres, que se sostiene por medio de una violencia legítima” (Weber, 1992 [1919]: 9).

Sin negar la importancia analítica de esta definición, el debate en el presente texto propone subvertirla tomando, precisamente, el camino opuesto al de Weber. Para esto me baso en las reflexiones de Chantal Mouffe (1999).

\footnotetext{
${ }^{3}$ La metodología etnográfica adoptada se basa en la concepción analítica de la situacionalidad del sujeto como el punto de partida de toda y cualquier observación etnográfica. Esta referencia a la situacionalidad es compartida con los paradigmas existencialistas en filosofía. En esto coincido con Simone de Beauvoir (2018 [1958]: 161; traducción propia), para quién solo la idea de situación "permite definir concretamente conjuntos humanos sin esclavizarlos en una fatalidad temporal". Así, el concepto de "situación" (y la situacionalidad) manifiesta la tensión insuperable entre las imposiciones que recaen sobre los sujetos y su capacidad de decidir sobre ellas para posicionarse, actuar y sobrevivir. Esta parcial "libertad", "es la propia modalidad de la existencia que, bien o mal, de una forma u otra, retoma por su cuenta todo lo que viene de afuera [...]. En compensación, las posibilidades concretas que se abren para las personas son desiguales; algunas solo tienen acceso a una pequeña parte de las que dispone el conjunto de la humanidad" (ibidem: 518). Diversos autores postmarxistas y postestructuralistas asumen la centralidad de esta noción de "situación" en la consecución de lecturas diacrónicas de los procesos sociales, buscando con ello captar la dialéctica entre la capacidad de determinación subjetiva y las constricciones estructurales (Kapferer, 2006). La importancia de este debate para la modalidad de narración antropológica que practico es fundamental, dado que fundamenta la dimensión intersubjetiva de la investigadora como sujeto político situado en los espacios y relaciones que narra y analiza.
} 
Considero que el final del siglo xx estuvo marcado por el desconcierto de los demócratas (neo)liberales, que habían creído en el triunfo definitivo del modelo jurídico liberal-demócrata y de su prototipo de razón universal, asumiendo que dicho triunfo eliminaría los conflictos étnicos, religiosos e identitarios; sin embargo, en un sentido radicalmente opuesto a sus pretensiones, se multiplicaron (Mouffe, 1999: 11). Su pretensiosa utopía se sostenía en la idea de que un consenso racionalista podría conducir a la eliminación del conflicto, la superación de toda forma de exclusión y, consecuentemente, de toda forma de "política convencional" (ibidem: 12). Por lo tanto, considero que la desaparición de la frontera y del antagonismo entre totalitarismo y democracia -demarcación fundamental para las concertaciones políticas de toda la segunda mitad del siglo xx-, desencadenó una profunda desestabilización de las sociedades declaradas occidentales a partir de la última década del siglo xx (ibidem: 13), moviendo las fronteras constituyentes de lo político hacia las definiciones de alteridad basadas en marcadores étnicos internos y externos a los Estados nación (ibidem: 15-16).

Pensando en estos procesos, en cómo incentivaron la creciente incorporación de enfrentamientos de alteridad xenófobos, racistas y misóginos, propongo establecer una diferenciación entre lo político, "ligado a la dimensión de antagonismo y hostilidad que existen en las relaciones humanas" que se manifiesta "como diversidad en las relaciones sociales", y la política, "que apunta a establecer un orden, a organizar la coexistencia humana en condiciones que son siempre conflictivas, pues están atravesadas por lo político" (ibidem: 13-14).

El giro propuesto por Mouffe instituye definiciones significativas. Primero, asume que "la política" es un "deber ser" que, al menos en los Estados democráticos, está atravesado por la disputa (por determinar las definiciones, representaciones y modos de poner en práctica este devenir). Simultáneamente, asume que "lo político" subsume la racionalidad de dominación (basada en el pragmatismo de fines que justifican medios), pero dirigiéndose a la coexistencia humana. Así, ofrece una lectura de la política (como "deber ser") que la interpone en una relación dialéctica con lo político (el "ser") y que, a través de la asunción de la inexorabilidad del conflicto entre ambos, permite superar a Weber. De esta forma, se asume que el conflicto es constitutivo de la política y de lo político, y que el consenso democrático no puede equivaler a su eliminación, como tampoco puede proyectar homogenizar la diversidad (ibidem: 16).

En este argumento, las identidades están siempre enmarcadas en un juego dialéctico que es ontológicamente relacional (Butler, 2011:39). Asumir la 
dimensión dialéctica de las identidades implica aceptar en estas una incompletitud constitutiva: que las identidades solo pueden existir en la fricción con otras (Butler, 2011: 39). En este sentido, el contacto conflictivo entre identidades en las democracias radicales propuestas por Mouffe (1999) asume que dichas identidades están en un proceso permanente de "fricción interétnica". Este último concepto fue propuesto por Roberto Cardoso de Oliveira (1963: 46), para referirse a la interacción entre aquellas identidades que mantienen "relaciones de oposición, histórica y estructuralmente demostrables". No obstante, no se trataría de relaciones "entre entidades opuestas, simplemente diferentes o exóticas, unas en relación con otras, pero contradictorias; esto es, que la existencia de una tiende a negar la de la otra" (ibidem). La fricción interétnica alude, precisamente, a la característica básica de esta situación de contacto. Los grupos o identidades en oposición, en fricción

También poseen sus propias dinámicas y sus contradicciones. De ahí entenderemos la situación de contacto como una "totalidad sincrética" o, en otras palabras, como situación de contacto entre dos poblaciones dialécticamente "unificadas" a través de intereses diametralmente opuestos, aunque interdependientes, por paradójico que esto parezca. (Cardoso de Oliveira, 1963: 46)

Así, las disputas entre identidades son estructurantes del proceso político -que por lo mismo estaría fuertemente amparado en la construcción de hegemonías políticas-, en su vinculación con las visiones de mundo y representaciones sociales. ${ }^{4}$ Esto implica asumir que la política y lo político se constituyen como relaciones intersubjetivas entre organizaciones, movimientos sociales y "un sinfín de sujetos hegemónicos y subalternos" (Grimson, 2019: 19). Entonces, el proceso político está, coartado por condiciones subjetivas. Esto implica que el proceso de constitución de las hegemonías opera desde un intersticio que extrapola, con creces, la dimensión más racional o racionalista de la experiencia de lo político. Por lo tanto, se trata de un problema de constitución de subjetividades políticas, que están articuladas a modo de "configuración de sensibilidades", como

\footnotetext{
${ }^{4}$ Cuando hablo de hegemonías políticas, remito al debate postgramsciano, sintetizado por Said (2004: 26-27): Gramsci ha efectuado una útil distinción entre sociedad civil y sociedad política según la cual la primera está formada por asociaciones voluntarias (o al menos racionales y no coercitivas), como las escuelas, las familias, los sindicatos; y la segunda, por instituciones estatales (el ejército, la policía y la burocracia central) cuya función dentro del Estado es la dominación directa. La cultura, por supuesto, funciona en el marco de la sociedad civil donde la influencia de las ideas, las instituciones y las personas se ejerce, no a través de la dominación, sino a través de lo que Gramsci llama consenso. La forma que adopta esta supremacía cultural es lo que Gramsci llama "hegemonía".
} 
Formas vividas de percepción y sensibilidad que no pueden ser derivadas de esquemas ideológicos o políticos. La potencia de esta idea radica en que las estructuras de sentimiento, aunque más difusas que una ideología, resultan tanto o más eficaces como guías para la acción: son aquello que genera atracción o repulsa, que componen lo bello o lo espantoso, pero no en el plano de lo normativo o del gran libro, sino en las vidas reales de las personas [...]. Sin embargo, tales corroboraciones no siempre tienen el peso específico de la palabra "estructura". Por ello, preferimos aludir a "configuraciones" de sensibilidades. (Grimson, 2019: 112-113).

En la configuración de estas sensibilidades y de las subjetividades políticas que de estas emanan (y que les da vida), la memoria ocupa un papel central siendo, por lo mismo, un elemento crucial en las disputas por la hegemonía política. La memoria implica una acción social -que, dialécticamente, es colectiva e individual- a través de la cual grupos y personas seleccionan los elementos (discursos, materialidades, performances, hechos, relación) que serán invocados como parte compositiva del sentido compartido (Fabian, 2007: 77-92). Esta dimensión contradictoria es precisamente lo que permite que la memoria se construya en el marco de relaciones sociales que atraviesan los sujetos y, a la vez, los conforman. Según Maurice Halbwachs (2004 [1968]), toda memoria se erige en una doble dimensión: por un lado, es individual y, por otro, colectiva. Como fenómeno individual la memoria se basa en la construcción de la situacionalidad del sujeto. Esta es, precisamente, el testimonio sensible, situado, derivado tanto de los recuerdos antiguos como de las experiencias sedimentadas por los sujetos y la producción coetánea y dinámica de su presencia en un contexto. No por casualidad Halbwachs (2004 [1968]: 25) afirma que, en lo que concierne a la memoria, somos "el primer testigo al que podemos recurrir". Ahora bien, esta dimensión individual es simultánea a la construcción social de la memoria en cuanto forma colectiva; es decir, en cuanto experiencia que extrapola esta dimensión individual:

Pero nuestros recuerdos siguen siendo colectivos y son los demás quienes nos los recuerdan, a pesar de que se trata de hechos en los que hemos estado implicados nosotros solos, y objetos que hemos visto nosotros solos. Esto se debe a que en realidad nunca estamos solos. No hace falta que haya otros hombres que se distingan materialmente de nosotros, ya que llevamos siempre con nosotros y en nosotros una determinada cantidad de personas que no se confunden. (ibidem: 26)

El acto de memorar tiene un par relativo, el "olvidar". La dialéctica entre recordar y olvidar marca la inscripción, en los discursos colectivos 
y públicos, de aquello que se entiende como plausible de configurar el entendimiento de las experiencias pasadas, a la vez que se trata de un recurso para interpretar las acciones en el presente y proyectarlas en el futuro (Fabian, 2007: 66). Entonces, memorar es un acto político que tiene su agencia, precisamente, en la práctica de la selección estipulada por la dialéctica entre estos dos verbos (ibidem: 97). Por ello, tal como ha dicho Karl Marx (1988), el control de las formas de narración del pasado son objeto de apropiación política por parte de aquellos grupos que se hacen con el dominio de un orden social ("los vencedores").

Pero este dominio sobre la producción del relato histórico debe engendrar una forma de producir la experiencia de los sujetos y grupos sociales: además de narrar una historia hegemónica, los vencedores disputan también la institucionalización de formas estándar de la memoria que obligan a la reinscripción subjetiva (e intersubjetiva) de la versión "oficial" de los hechos a modo de configuraciones de sensibilidad. Esta es la forma que Johannes Fabian (2007: 94) denomina "memoria pública". Esta coexiste conflictivamente con las memorias de quienes, no constituyendo los grupos hegemónicos, disputarán los mecanismos de representación y de selección del pasado. Esta segunda forma de memoria, de rasgos contrahegemónicos, es la que Fabian (ibidem) denomina "colectiva".

La memoria pública goza de muchos más elementos de propagación: suele contar con todos los instrumentos institucionales estatales y no estatales que los dominadores reúnen. La educación formal es uno de ellos, ya que a través de la misma se inculcan narraciones históricas y se fomentan patrones específicos de olvido y recuerdo, estandarizándose los procesos de memoria. Generalmente, la estandarización educacional de la memoria se legitima a partir de un discurso modernizante -civilizatorio, racionalista- que niega la validez empírica del conocimiento popular, del sentido común y, además, de aquellos mecanismos y performances -músicas, bailes, narrativas, relaciones- que alimentan la memoria colectiva.

Este debate nos remite a la diferenciación que hace Paulo Freire (1996) entre educación pública -(re)productora de la memoria pública- y educación popular -bastión de la memoria popular-. Para el autor, la educación pública desafortunadamente tiende a violar la experiencia, los sentidos y los saberes populares; mientras que la educación popular busca, precisamente, centralizarlos. Según Freire (1996: 107), en una propuesta educacional emancipatoria que fomente en los sujetos concepciones de mundo situadas desde su propia praxis y experiencia, la educación pública debe incorporar la popular y entre ambas debería existir una sinergia. En este sentido, Freire (ibidem: 108) vincula la capacidad transformadora de la educación 
al reconocimiento de su papel en la formación de sujetos políticos que son capaces de situarse en esta intrincada dialéctica: entre la percepción de su lugar y acción en el mundo, y el reconocimiento de las estructuras condicionantes que la limitan, aunque sin impedirla del todo. Con esto, propone que esta educación emancipadora debe superar la

Visión mecanicista de la historia, que guarda en sí la certeza de que el futuro es inexorable, de que el futuro viene como está dicho que vendrá, que niega todo poder a la educación antes de la transformación de las condiciones materiales de la sociedad. Del mismo modo que niega toda la importancia mayor de la subjetividad en la historia. (Freire, 1996: 108).

De este modo, la superación de las formas mecanicistas de la historia implica la configuración de una práctica de la memoria que entienda la "relación dialéctica entre la consciencia y el mundo" (ibidem). La consciencia del ser, finalidad y devenir de la pedagogía de la esperanza propuesta por Freire, exigiría esencialmente a los sujetos la capacidad autocrítica de situar su propia experiencia como elemento productor de la memoria y, al menos, de producir formas de narrativa histórica que devengan de esta consciencia de su situacionalidad y experiencias políticas en el mundo:

Nadie deja su mundo, adentrado por sus raíces, con el cuerpo vacío y seco. Cargamos con nosotros las memorias de muchas tramas, el cuerpo mojado de nuestra historia, de nuestra cultura; la memoria, a veces difusa, a veces nítida, clara, de las calles de la infancia, de la adolescencia; el recuerdo de algo distante que de repente se destaca nítido frente a nosotros, en nosotros, un gesto tímido, la mano que se estrechó, la sonrisa que se perdió en un tiempo de incomprensiones, una pura frase posiblemente ya olvidada por quien la dijo. (Freire, 1993: 30)

La conciencia de los sujetos, su capacidad de agencia, estarían mediados, precisamente, por lograr acceder a las memorias propias, y la educación debería ser, según Freire, el vehículo de esta hazaña. No obstante, para el autor se trata de una hazaña a realizar con el cuerpo (que es el que se impregna, el que se moja con la memoria) y con la palabra. A través de su argumento podemos vincular la constitución de la subjetividad política, las configuraciones de la sensibilidad y la memoria a la conciencia del lugar en el mundo a la que deberíamos acceder a través de la educación. Por ahora, habiendo retenidos estos conceptos, dejémoslos reposar para adentrarnos en mi experiencia etnográfica en la Triple Frontera del Paraná. Los retomaré en las consideraciones finales. 


\section{Etnografía en la frontera}

A continuación narro dos momentos de mi trabajo de campo. Primero una escena vivida en Foz de Iguazú, cuando acompañé presencialmente el despliegue de los discursos del odio en el curso de las votaciones presidenciales brasileñas. A través de este relato, doy muestra de la intensidad/ /transversalidad de estas configuraciones de sensibilidad en la ciudad. En la segunda escena narro mis conversaciones con Carlos, un joven negro de Foz que se adhería a estos discursos del odio.

\section{Las elecciones y el odio}

A las 22:00 del día 7 de octubre del 2018, las televisiones brasileñas anunciaban que el $99 \%$ de las urnas electorales ya habían sido contabilizadas. El candidato de la extrema derecha a la presidencia, Jair Bolsonaro (Partido Social Liberal, PSL), contaba con el 46,2 \% de los votos, seguido de Fernando Haddad (Partido de los Trabajadores, PT) con un 29,1\% y de Ciro Gomes (Partido Democrático Laborista, PDT) con un 12,5\%.

Bolsonaro obtuvo un número superior de votos en casi todos los estados que componen el país. Estuvo muy cerca de vencer sin tener que enfrentar una segunda vuelta. La campaña electoral estuvo muy marcada por las informaciones falaces que circularon intensamente por Internet y a través de cadenas de WhatsApp. La legislación brasileña aún no había sufrido las revisiones necesarias; no se había discutido sobre cómo legislar acerca de estas nuevas tecnologías y cómo asimilar sus potencialidades a las reglas del juego democrático.

Por la misma razón, las elecciones estuvieron absolutamente influenciadas por una fuerte campaña de contrainformación. Las noticias falsas alimentaron fantasías terroríficas en la mente de un electorado que ya tenía demasiadas razones para temer a sus representantes políticos. El resultado fue el persistente descrédito sobre las instituciones del Estado y, sobre todo, la construcción de un sentimiento muy generalizado de que no había nada más que perder. Se generó un asustador consenso social para aceptar y hacer uso de medidas violentas para "protegerse" de la "catástrofe" en que se había transformado el país. Esta sensación de "estado de excepción”, permitió que el discurso y las prácticas de muchos fuesen una "vía libre" para defender todo tipo de atrocidades que, en tiempos de calma y regulación, serían desterradas del repertorio social. Una parcela increíblemente grande del electorado brasileño vio en este desliz ético y moral una puerta abierta para liberar sus deseos de dominación de larga data: el deseo de castigar a los negros, los indígenas, las mujeres y los pobres en general. El racismo, la misoginia y la aporofobia se adueñaron de la esfera pública (Aquino, 2019; 
Casimiro, 2018; Ezequiel et al., 2019; Girelli, 2019; Müller, 2019; Neves, 2018; Solano, 2019).

El día de las votaciones yo me encontraba fuera de mi distrito de origen y tuve que acudir a un local de votación en Foz, para explicar mi situación ante el Tribunal Electoral. En Brasil, a este procedimiento se le denomina popularmente "justificar el voto". Me levanté temprano para desayunar en la pensión familiar donde que me hospedaba. El dueño del establecimiento me indicó cómo podía llegar al local de votación más cercano, en la escuela pública Bartolomé Mitre, en el centro de Foz.

Al llegar al colegio, lo primero que me sorprendió fue encontrarme con un grupo de votantes de Bolsonaro en la puerta, aglomerados alrededor del policía militar designado que estaba de guardia en el local. Eran cinco hombres y una mujer con camisetas de la selección brasileña de fútbol, la bandera del país y pegatinas del candidato pegadas en el lado izquierdo del pecho. Los colores de la bandera se habían convertido en un elemento de identidad para los electores de la extrema derecha. Hablaban animadamente, convencidos de la victoria de su candidato, que emprendería una campaña para "limpiar el país", eliminando a todos los ladrones. Estaban hablando de exterminio sumario: "hay que matarlos; no hay que entregarlos a la justicia; hay que matarlos y exhibirlos en las plazas como ejemplo", manifestó uno de ellos, ante la efusiva aprobación de los demás. Mientras observaba la escena, se acercó al grupo una señora con varias pegatinas del candidato en su blusa. Uno de los miembros del grupo la llevó aparte, justo a mi lado, diciéndole: "¿cómo se te ocurre venir con una blusa roja? No puedes vestirte de rojo. ¿Acaso piensas que estás en Venezuela?”. La señora se disculpó inmediatamente por su "equivocación" y se fue a casa para cambiarse de ropa.

Decidí alejarme de aquel grupo y cumplir con mis obligaciones. El colegio estaba repleto; las filas para votar y para "justificar" eran las mismas, por lo cual tuve que compartir la espera con electores que, a diferencia mía, iban a depositar su voto. La mayor parte eran partidarios del candidato de extrema derecha. Me tocó estar en la fila, escuchando sus debates, durante casi dos horas.

Delante de mí, un grupo de tres hombres y dos mujeres conversaban sobre las elecciones y el futuro del país. Uno de ellos, al hablar del ministro del Tribunal Supremo de Justicia, Gilmar Mendes, manifestó que habría que asesinarlo y tirarlo al mar (reiterando el apoyo a los asesinatos sumarios). Todos estuvieron de acuerdo con sus comentarios y, profundizando en estas "reflexiones", uno de ellos dijo que debían soltar a Lula para que también alguien lo matara. Las mujeres, a su vez, añadieron sus comentarios sobre 
las militantes del partido de Lula, llamándolas "putitas" (mencionaron a una de las senadoras de la República, Gleise Hoffmann, que es la actual presidenta del PT, y a la líder del Partido Comunista de Brasil, Manuela D’Ávila). En referencia a las marchas de las mujeres contra Bolsonaro, que habían tomado las calles del país la semana anterior a la votación, todos estaban de acuerdo en que "todas eran unas feministas ordinarias", "que no creen en Dios". Uno de los señores reiteró que no se puede blasfemar contra Jesús y, como para dar por cerrado el asunto, señaló el eslogan de campaña de Bolsonaro estampado en su camiseta: "Dios sobre todos y Brasil sobre todo". Esta frase es idéntica a la que usó Hitler en la publicidad del partido nazi: Deutschland über alles [Alemania por encima de todo].

La conversación prosiguió por derroteros cada vez más virulentos: que los pobres y los negros no saben votar y que no deberían hacerlo; que el nordeste del país (la zona más pobre y con mayoría de votantes del PT) no debería participar en las votaciones; que todos los del nordeste brasileño deberían irse a Cuba o a Venezuela; que los brasileños que viven en el extranjero no deberían tener derecho a voto, ya que, si no amas Brasil y lo abandonas, no deberías tener derecho al voto ("Brasil, ámalo o déjalo" fue la frase utilizada por la Junta Militar en los años 1970, para justificar el exilio de opositores políticos).

Mientras escuchaba, me fui dando cuenta de que casi todos los que llegaban vestían camisetas del candidato de extrema derecha. Vi un pequeño grupo de electores de Ciro Gomes (PDT) con pequeñas pegatinas, pero nadie que no fuera votante de Bolsonaro tuvo el coraje de iniciar alguna conversación. La gente que no estaba de acuerdo con estas ideas tuvo miedo de hablar. Dos escenas que sufrí en primera persona, me van a servir para ilustrar lo anterior.

La primera ocurrió cuando estaba en la fila. Mientras el grupo seguía hablando animadamente de torturar y matar a los opositores, avanzó hacia nosotros una señora mayor. Andaba lentamente con su bastón y vino a saludar al caballero que estaba justo detrás de mí, diciéndole: "voté para arreglar este país con tiros porque solo con tiros se va a arreglar este país". El señor respondió alegremente que sí, juntamente con el grupo que estaba delante de mí y los que estaban a los lados; fui la única que se quedó en silencio. Uno de los hombres del grupo me miró fijamente diciendo: "tú no dijiste nada, ¿eres izquierdista?". En ese momento supe que no podía

\footnotetext{
5 "Izquierdista" es una expresión despectiva que se viene utilizando desde hace unos dos años en Brasil, por los movimientos de derecha y extrema derecha, para referirse a los que apoyan posiciones políticas de centro y de izquierda.
} 
decir nada; temí decir que sí, que soy de izquierda; temí por lo que me pudiera pasar al salir sola de aquella fila de votación. La segunda escena ocurrió unos minutos después, cuando salí de la sala de votaciones. Tras cruzar la puerta, en el pasillo del colegio, un señor partidario de Bolsonaro me retuvo y me preguntó: "tú acabas de votar, ¿verdad?". Antes que pudiera decir alguna cosa, me sujetó por el brazo y añadió: "tú no tienes cara de haber votado por Bolsonaro; no te veo feliz por nuestro país; no me vengas a decir que eres una izquierdista".

Voto en Brasil desde los 16 años y jamás he visto comportamientos de esta naturaleza en un día de elecciones. Me quedé un buen rato observando las filas, la gente y el lugar. Empezó a llover copiosamente y la lluvia parecía -perdonando la mala metáfora- la gota que colmaba el vaso. Regresé a la pensión enmudecida y, lógicamente, empapada.

Es cierto que Foz se sitúa en el estado de Paraná, que desde hace tiempo se viene caracterizando por la posición conservadora de sus electores, pero el colegio al que fui era céntrico y a él acudieron electores de diferentes estratos socioeconómicos, oriundos de diferentes zonas del país (Foz es una ciudad de migración internacional e interna). Toda esta heterogeneidad coincidía únicamente en la adhesión a una cosmovisión fascista. Esta cosmovisión está caracterizada, entre otras cosas, por la construcción de una fractura ("nosotros versus los otros") (Todorov, 1991) y por la deslegitimación sorda, incapaz de oír y registrar cualquier argumento que no coincida con el deseo de violencia hacia aquellos que son imaginados como "los otros". Además, hay que decir que los apoyantes de Bolsonaro también buscaban satisfacer privilegios que, en una sociedad con normas democráticas, sencillamente no se pueden permitir. En los diálogos, escuché cosas de este género: "tengo una empresa y los empleados votan al PT. ¡Claro! Quieren tener aguinaldo y licencia de maternidad, como si esto fuera posible en un país como el nuestro. No entienden que no se puede tener todo".

La frase parecía salida de las novelas del siglo XIX que retrataban la vida y la manera de pensar de las élites esclavistas. Terminé el día preguntándome cómo los afrobrasileños, los indígenas y otros grupos que son atacados por estos discursos del odio podían sentirse identificados con estos discursos. Mi experiencia con Carlos ${ }^{6}$ daría respuesta, en parte, a estos interrogantes.

\section{Carlos}

En las tres semanas que siguieron a este día de votación, estuve desarrollando mi etnografía junto a la red humanitaria que atiende a los/las trabajadores/as

${ }^{6}$ El nombre real se ha cambiado por un seudónimo para proteger la identidad del colaborador. 
migrantes fronterizos. Esta red está coordinada por las hermanas de una congregación religiosa católica cuya sede está ubicada en Foz, en las inmediaciones del puente que conecta con Ciudad del Este. Los/las trabajadores/as de esta red humanitaria asesoran a los migrantes de cualquier nacionalidad sobre sus derechos, la atención de los servicios públicos, los trámites de documentos y la regularización de su situación migratoria.

Durante mi primera semana en el terreno, entrevisté a los sacerdotes y las hermanas responsables de esta red y todos coincidían en manifestar su enorme preocupación con las dimensiones que los discursos de odio estaban tomando. Una de las hermanas me explicó que la conflictividad se había desatado de forma muy preocupante y para evitar que las discusiones devinieran en peleas abiertas, había pedido a las personas que frecuentaban el centro de atención que no hablaran de política en el local. Esta misma hermana me señaló a Carlos, un joven negro recién licenciado en Derecho, que trabajaba en la red atendiendo a los migrantes. Con inquietud, ella me explicó que no podía entender por qué razón un joven como él reproducía las consignas de la campaña del candidato de la extrema derecha.

Su comentario me llamó la atención y despertó mi curiosidad. En el centro de atención compartí varios días de trabajo con Carlos, acompañándolo mientras atendía a las mujeres migrantes (a las que luego yo entrevistaba). Desatendiendo las recomendaciones de la hermana de la caridad, aproveché estas jornadas para conversar con Carlos y comprender por qué apoyaba a Bolsonaro.

Carlos había empezado a trabajar a los 15 años, provenía de una familia obrera residente en la periferia de Foz. Había estudiado la primaria y la secundaria en colegios públicos. La educación deficitaria impartida en estos colegios, según me explicó, dificultó mucho su entrada en la universidad pública, ya que en Brasil el acceso se hace mediante a un examen muy exigente (el "vestibular"). Sin embargo, su suerte cambiaría gracias a una política específica que, si bien fue implementada en la presidencia de Fernando Henrique Cardoso, experimentó una gran expansión en el segundo mandato del gobierno de Luiz Inácio Lula da Silva (2007-2011). Así, Carlos logró estudiar la carrera de Derecho con enorme esfuerzo y gracias a la creación de un programa de incentivo denominado Fundo de Financiamento ao Estudante do Ensino Superior, que facilitaba el acceso de los estudiantes de medianos y bajos recursos, a las universidades privadas. Él fue la primera persona de su familia en acceder a los estudios universitarios. Su madre, una mujer negra, también accedió por primera vez a los derechos laborales gracias a las reformas legales del segundo mandato de Dilma Roussef (2015-2016), también del PT. 
No obstante, nada de esto impedía que Carlos fuera un decidido apoyante de Bolsonaro. En nuestras conversaciones repetía machaconamente que los gobiernos del PT habían sido "lo peor que había ocurrido en toda la historia del país"; "lo peor que había pasado para la gente". Estas afirmaciones suscitaron en mí muchos interrogantes. En un país donde la esclavitud mató y torturó sistemáticamente a hombres y mujeres de raza negra durante más de tres siglos (entre 1530 y 1888); con un pasado reciente de más de dos décadas de dictadura militar (entre 1964 y 1986) en la que se institucionalizó la violencia contra los negros y los pobres, acentuándose fuertemente la desigualdad social que sufrían, y tratándose de un afrobrasileño, ¿cómo era posible que Carlos pensara que los gobiernos democráticos del siglo XXI habían sido lo peor de la historia nacional?

Intrigada por la forma en que Carlos interpretaba el lugar de los afrobrasileños en la campaña electoral, le mostré grabaciones de los discursos de Bolsonaro, donde el candidato agredía a los afrodescendientes (con frases que aducían que ellos "no sirven para nada, ni siquiera para procrear") y especialmente a las mujeres negras (a quienes, por ejemplo, ha llamado "promiscuas", entre varios e irreproducibles calificativos). Los ojos de Carlos se llenaron de lágrimas al escuchar estos discursos. "¿Él está hablando de los negros?”, me preguntó incrédulo y con voz trémula, al ver uno de los videos. Hablamos sobre las declaraciones en las que Bolsonaro consideraba a los negros y a los afrodescendientes como minorías en Brasil y, por lo tanto, que él se imaginaba un país de mayoría blanca (esta es una imagen que las élites reproducen desde la época colonial). La reacción de Carlos frente a la cuestión racial en los discursos de la extrema derecha, me hizo comprender que en su apoyo a Bolsonaro no estaba computada su propia experiencia como hombre negro en la frontera brasileña. Carlos apoyaba discursos y posicionamientos que le resultaban tan violentos que le hacían llorar.

Precisamente en una de estas conversaciones, él me interpeló indagando cuál era mi posición con relación a estos discursos; quería entender el punto de vista de una mujer blanca, descendiente de colonos italianos. Su interpelación detonó en mí una serie de reflexiones sobre algo que me resultaba del todo inexplicable: el apoyo de muchos de mis familiares a Bolsonaro. Nos parecía curioso que tanto su familia como la mía, ocupando lugares tan dispares en la jerarquía creada por el conflicto racial en Brasil, coincidieran en esta perspectiva política.

A partir de esta conversación, propuse a Carlos un ejercicio para nuestro tiempo libre durante el trabajo en el centro de atención a migrantes. Le pedí que fuéramos reconstruyendo nuestras vidas desde el presente hasta tres décadas atrás, recordando qué hacíamos, qué cosas podíamos o no consumir, 
cómo era la vida en nuestro barrio, en nuestra casa y la experiencia de las personas de nuestro entorno. Así fue como Carlos me reconstruyó su vida en 2018, 2012, 2002 y 1992. Este ejercicio de "inventario" de nuestras trayectorias lo hicimos paulatinamente, día a día. Lo terminamos un día antes de que yo me fuera de la frontera, cuando una fuerte tormenta nos dejó a la hermana de la caridad, a Carlos y a mí, encerrados en el centro de atención sin poder desplazarnos. La hermana participó en este ejercicio contándonos su vida y su experiencia en las décadas de 1980 y 1970; sus relatos sobre la represión militar en la dictadura chocaron a Carlos, que carecía absolutamente de referencias sobre estas circunstancias (por ejemplo, nunca lo había estudiado en el colegio). Ese día, cuando nos despedimos, Carlos me miró atentamente y dijo: "nosotros vivíamos mejor en los gobiernos del PT". Me abrazó y me dio las gracias. Este "nosotros", me explicó, se refería a él y a su familia, pero también a toda la población negra de Brasil.

\section{Inventarios de la memoria y educación para la autonomía}

Gracias a Carlos pude entender un punto central que debemos tematizar los educadores si queremos hacer frente al avance de los discursos del odio entre sujetos que, como mi interlocutor, se convertirán precisamente en las primeras víctimas de un programa político neofascista como el que defiende Bolsonaro. Mis diálogos con Carlos me permitieron comprender que él no era capaz de narrar su propia experiencia en el mundo como una fuente legítima de conocimientos, a partir de los cuales posicionar su orientación política. Su experiencia vital no estaba integrada con su discurso de adhesión política. En este sentido, su experiencia de la política está basada en la asunción de una narrativa histórica externa a las realidades vividas por él y por sus familiares: una historia pública que ignora la historia popular de la población negra en las periferias de Brasil. Asimismo, la memoria de las experiencias pasadas y la forma en que Carlos registra sus memorias de las experiencias presentes, niega la vigencia de su condición: el sujeto se adhiere a un modelo de olvido que impide la conciencia sobre su propia vivencia en el mundo -aquella que, como decía Freire (1993: 30), se "impregna en el cuerpo", "lo moja" entero-. De este modo, la memoria de Carlos reproduce patrones hegemónicos de la memoria pública a costa de inhabilitar sus propias narraciones sobre la historia.

Este tipo de incapacidad por parte de los sujetos para darle ontología política a sus propias experiencias es una estructura simbólica que compartimos diversos grupos en Brasil. Históricamente, en este país hemos conformado una experiencia de la política en la cual sujetos de diversos orígenes y posicionamientos (de clase, religiosos, de género) sufren una 
interdicción simbólica que les impide acceder a sus propios "inventarios" de la memoria. Este tipo de interdicto simbólico puede ser caracterizado como un proceso de "forclusión".

La forclusión es un concepto lacaniano que alude a aquellos significantes que son borrados por los sujetos -tanto de las dimensiones conscientes como inconscientes-. Se trataría del mecanismo que está en el origen de la psicosis y, según Lacan (1956), se produciría por la exclusión total de la figura paterna, la incapacidad del sujeto para registrar esta figura en la primera infancia. Desde el feminismo crítico, Rita Segato (2013: 179-210) expande el uso del concepto para explicar que la violencia patriarcal se ampara en un proceso de forclusión del elemento femenino y deriva en el ocultamiento progresivo de los saberes, conocimientos, prácticas y visiones del mundo femeninos. Ella lo ejemplifica claramente cuando analiza la forclusión de la figura de las mujeres negras brasileñas (trabajadoras domésticas y nanas) cuyo afecto, trabajo y cuidado desaparecen de la percepción de la realidad de aquellos hombres y mujeres blancos en cuya crianza participaron.

Lógicamente, este mecanismo actúa construyendo un grupo de poder prototípicamente representado por hombres y mujeres blancos de las élites nacionales, cuyas percepciones de la realidad, basadas frecuentemente en la negación de los/las "otros/as", asumen el carácter de "única representación posible" y son elevadas a la condición de universalidad. Así, la forclusión afecta la autopercepción de aquellos que no pertenecen a este grupo prototípico, impidiendo que puedan conformar sus propias lecturas y narrativas sobre su lugar en su propia historia y en la de su país. Pero también afecta a las propias elites, cuyas subjetividades políticas se basan y demandan de los sujetos actuar con violencias reincidentes que empujan a los "otros" a la periferia de la representación política. Unos y otros son violentados y la fractura permanente entre los sujetos es el gancho interno que permite que los discursos del odio sean tan poderosamente movilizadores en Brasil.

Desde mi perspectiva y apoyándome en la propuesta emancipadora de Freire (1993, 1996), la educación es la principal salida para detener este tipo de reproducción de la forclusión de los sujetos políticos; pero se trata de una educación pensada como un ejercicio de memoria que cultiva en las personas la capacidad de tomar consciencia de su acción en el mundo, sin con ello despreciar la existencia de las estructuras que limitan, conforman o potencian esta acción. En esta propuesta educacional, quisiera sugerir que uno de los caminos centrales alude a la construcción de herramientas que permitan a los sujetos centralizar su consciencia acerca de la vinculación 
entre la experiencia social, los ejercicios de la memoria y la construcción de los relatos históricos.

Un ejercicio en este sentido consiste, precisamente, en recuperar aquello que Walter Benjamin (1994: 197) denominó como "el arte de narrar" que, como bien observaba, está en vías de extinción. Mi ejercicio con Carlos, el hecho de que reconstruyéramos nuestras experiencias narrándolas década por década a lo largo de nuestras jornadas de trabajo, apuntaba, precisamente, en esta dirección: reconstruir narrativamente un inventario de su memoria que reincorporara su propia experiencia social como fuente de posicionamiento político. Y aún más: apuntaba a un posicionamiento político que, como bien definió Grimson (2019), es de carácter intersubjetivo, pues si bien es un sujeto concreto el que narra su historia y memoriza su experiencia en este acto de relatar, el objetivo del ejercicio es el diálogo con un/una otro/a que, en este mismo proceso, también recuerda, narra y memoriza.

Permítanme que explique estas afirmaciones recurriendo directamente a las reflexiones que las inspiran, tejidas por Gramsci (1975: 1363; traducción propia):

El punto de partida de cualquier elaboración crítica es la toma de conciencia de lo que uno realmente es; es decir, la premisa "conócete a ti mismo" en tanto que producto de un proceso histórico concreto que ha dejado en ti infinidad de huellas sin, a la vez, dejar un inventario de ellas. Por tanto, es un imperativo comenzar por recopilar ese inventario.

Po lo tanto, me refiero a que una propuesta educativa en contra del fascismo, a favor de la emancipación y la autonomía, debe necesariamente trabajar con los sujetos los procesos de narración de sus genealogías: su capacidad de dar ontología discursiva, performática y realizable a sus propias experiencias, convirtiéndolas en un catálogo abierto de interpretaciones del mundo y de su posicionamiento en él.

Retomando la perspectiva gramsciana, esto implica la capacidad de acceder también a la comprensión de que las experiencias de los sujetos se constituyen desde genealogías históricas: desde los procesos que han atravesado nuestros antepasados, nuestras compañeras y compañeros, los espacios en los cuales vivimos, trabajamos y transitamos. En este sentido, la educación antifascista debe avanzar decididamente hacia el ejercicio de inventarios históricos.

No obstante, permítanme expandir esta idea de inventario, para concebirla desde claves que incorporan las heterogéneas maneras de narrar y de establecer este proceso compartido de la narración: la música, los bailes, 
las prácticas lúdicas y los juegos. Si la memoria es como el agua que moja el cuerpo de los sujetos, si las experiencias de la política ocurren a partir de las configuraciones de sensibilidad, como lo explicitaba Grimson (2019), entonces los inventarios deben apuntar a formas de diálogo sobre la memoria (personal y colectiva; pública y popular) que excedan las limitaciones de las definiciones logocéntricas y racionalistas.

Considerando estas reflexiones, finalizo este texto proponiendo definir la educación para la autonomía como un ejercicio político coparticipativo a partir del cual sujetos diferenciados intercambian saberes de diferentes registros para proponer, construir y potenciar: primero, su capacidad de situarse en el mundo, en las relaciones sociales, a partir de un posicionamiento autónomo coherente con su propia experiencia y, a la vez, con la historia personal y colectiva que lo conforma, que da sentido histórico a su trayectoria; segundo, la capacidad de reconocer, en la heterogeneidad de las autonomías, aquellos potenciales lazos que nos unen y aquellos mecanismos que nos permiten, contemplando la variedad de sujetos e inclinaciones, constituir una base colectiva, compartida y consensuada activamente; es decir, que la educación sería el instrumento a partir del cual creamos los medios y mecanismos de diálogo entre las diferentes autonomías en pro de la construcción de lo colectivo; y tercero, es también en la educación donde producimos las herramientas para convivir, dialogar y potenciar que el conflicto -característica ineludible de nuestra heterogeneidad- pueda ser incorporado como parte de nuestra vida colectiva y como un alimento para esta.

Revisado por José Morales

\section{Referencias bibliográficas}

Aquino, Filipe (2019), "Ódio, combustível patológico", Galáxia - Revista do Programa de Pós-graduação em Comunicação e Semiótica, 40, 180-183.

Benjamin, Walter (1994), Magia e técnica, arte e política: ensaios sobre literatura e história da cultura. São Paulo: Brasiliense. Traducción de Sergio Paulo Rouanet.

Burawoy, Michael (1998), "The Extended Case Method", Sociological Theory, 16(1), 4-33.

Butler, Judith (2011), "Replantear el universal: la hegemonía y los límites del formalismo”, in Judith Butler; Ernesto Laclau; Slavoj Žižek, Contingencia, hegemonía, universalidad. Diálogos contemporáneos en la izquierda. Buenos Aires: Fondo de Cultura Económica, 19-50. Traducción de Cristina Sardoy y Graciela Homs.

Cardin, Eric (2012), "Trabalho e práticas de contrabando na fronteira do Brasil com o Paraguai”, Revista Geopolíticas, 3(2), 207-234. 
Cardoso de Oliveira, Roberto (1963), “Aculturación y fricción interétnica”, Revista América Latina, 6(3), 33-46.

Casimiro, Flávio (2018), "As classes dominantes e a nova direita no Brasil contemporâneo”, in Esther Solano (comp.), O ódio como política: a reinvenção das direitas no Brasil. Rio de Janeiro: Boitempo, 42-48.

de Beauvoir, Simone (2018), A força da idade. Rio de Janeiro: Nova Fronteira. Traducción de Sergio Milliet [orig. 1958].

Ezequiel, Vanderlei de Castro; Cioccari, Deysi; Coelho, Cláudio Novaes Pinto (2019), "O pensamento conservador e as manifestações de ódio na cena política brasileira", Estudos de Sociologia, 24(46), 267-286.

Fabian, Johannes (2007), Memory against Culture: Arguments and Reminders. Durham: Duke University Press.

Fogel, Ramón (2008), "La región de la triple frontera: territorios de integración y desintegración”, Sociologías, 20, 270-290.

Frankenberg, Ronald (2006), "A Bridge over Troubled Waters, or What a Difference a Day Makes”, in Theodore M. S. Evens; Dan Handelman (comps.), The Manchester School. Practice and Ethnographic Praxis in Anthropology. New York: Berghahn Books, 202-222.

Freire, Paulo (1993), Pedagogía de la esperanza: un reencuentro con la pedagogía del oprimido. Buenos Aires: Siglo XXI.

Freire, Paulo (1996), Política y educación. Buenos Aires: Siglo XXI.

Giménez Béliveau, Verónica (2014), "El relato pionero. Procesos sociales en las fronteras Argentina/Paraguay/Brasil”, in José Manuel Valenzuela Arce (coord.), Transfronteras. Fronteras del mundo y procesos culturales. Tijuana: COLEF, 197-216.

Girelli, Luciana Silvestre (2019), "Discursos contra Lula e o PT: expressões do ódio no cenário político brasileiro no pré-impeachment de Dilma Rousseff”, Idealogando, 2(2), 27-47.

Gluckman, Max (2006), "Ethonographic Data in British Social Anthropology", in Theodore M. S. Evens; Dan Handelman (comps.), The Manchester School. Practice and Ethnographic Praxis in Anthropology. New York: Berghahn Books, 13-22.

Gramsci, Antonio (1975), Quaderni dal cárcere. Edición de Valentino Gerratana. Turin: Einaudi Editore.

Grimson, Alejandro (2019), ¿Qué es el peronismo? Buenos Aires: Siglo XXI.

Guber, Rosana (2001), La etnografía: método, campo y reflexividad. Buenos Aires: Editorial Norma.

Halbwachs, Maurice (2004), La memoria colectiva. Zaragoza: Prensas Universitarias de Zaragoza [orig. 1968].

Kapferer, Bruce (2006), "Situations, Crisis, and the Anthropology of the Concrete: The Contribution of Max Gluckman”, in Theodore M. S. Evens; Dan Handelman 
(comps.), The Manchester School. Practice and Ethnographic Praxis in Anthropology. New York: Berghahn Books, 94-117.

Lacan, Jacques (1956), La forclusión del nombre del padre. Seminario III la Psicosis. Barcelona: Paidós.

Marx, Karl (1988), El Dieciocho Brumario de Luis Bonaparte. Buenos Aires: Editorial Grijalbo. Traducción de Elisa Chiliá.

Mitchell, Clyde (2006), "Case and Situation Analysis", in Theodore M. S. Evens; Dan Handelman (comps.), The Manchester School. Practice and Ethnographic Praxis in Anthropology. New York: Berghahn Books, 23-44.

Mouffe, Chantal (1999), El retorno de lo político. Comunidad, ciudadanía, pluralismo, democracia radical. Barcelona: Paidós. Traducción de Marco Aurelio Galmarini Rodríguez.

Müller, Angelo (2019), "Brasil polarizado: os discursos de incitação ao ódio na campanha presidencial de 2014". Tesis de Doctorado en Comunicación Social, Pontificia Universidade Católica do Rio Grande do Sul, Porto Alegre, Brasil.

Neves, Raphael (2018), "Joga pedra na Judith: discursos de ódio e populismo", Cadernos Pagu, 53, e185307.

Portantiero, Juan Carlos (1982), "Los escritos políticos de Max Weber: la política como lucha contra el desencantamiento”, Desarrollo Económico, 22(81), 431-436.

Renoldi, Brígida (2014), "Conceptos que hacen el estado: crimen organizado y prácticas policiales en la Triple Frontera”. Actas del Seminario del Programa de Estudios sobre Saberes de Estado y Elites Estatales. Buenos Aires, octubre.

Said, Edward (2004), Orientalismo. Buenos Aires: Debolsillo. Traducción de María Luisa Fuentes.

Segato, Rita Laura (2013), La crítica de la colonialidad en ocho ensayos. Y una antropología por demanda. Buenos Aires: Prometeo.

Solano, Esther (2019), "La bolsonarización de Brasil”, Documentos de Trabajo IELAT, 121.

Todorov, Tzvetan (1991), Nosotros y los otros. Reflexiones sobre la diversidad humana. Ciudad de México: Siglo XXI. Traducción de Martín Mur Ubasart.

Weber, Max (1992), La politica como profesión. Madrid: Espasa Calpe. Traducción de Joaquín Abellán [orig. 1919]. 
Recibido: 01.07.2019

Aceptación comunicada: 06.12.2019

\author{
Menara Guizardi \\ CONICET - Consejo Nacional de Investigaciones Científicas y Técnicas, Instituto de \\ Altos Estudios Sociales, Universidad Nacional de San Martín I Universidad de Tarapacá \\ Avenida Presidente Roque Saenz Peña, 832 (Edificio Volta), 6 Piso, C1035AAP, \\ Ciudad Autónoma de Buenos Aires, Argentina \\ Contacto: menaraguizardi@yahoo.com.br \\ ORCID: https://orcid.org/0000-0003-2670-9360
}

\section{Education for Autonomy: Inventories of Memory in the Context of the Turn to the Extreme Right in Brazil}

The article addresses the confluence between education and politics, reflecting on the role of social memory in Brazil, where the extreme right advances with the support of voters who adhere to hate speech. First, I will conduct a theoretical debate on the relationship between politics, memory and education, thus framing the categories that guide the reflections developed throughout the text. Second, I will narrate my ethnographic experience in the Brazilian presidential elections of 2018 and my dialogue with Carlos, a young black man from the Brazilian city of Foz do Iguaçu, recipient of educational aid from the government of the Workers' Party and a Bolsonaro voter. In the final remarks, I will identify the place of social memory and the "inventories of the memory" as a tool for prevailing, from education to the political foreclosure of the subjects.

Keywords: autonomy; Brazil; education; extreme right (politics); memory; social inequality.

\section{Éducation pour l'autonomie: inven- taires de la mémoire dans le contexte du virage à l'extrême droite au Brésil}

Cet article aborde la confluence entre l'éducation et la politique en réfléchissant sur le rôle de la mémoire sociale au Brésil, où l'extrême droite avance avec le soutien des électeurs qui adhèrent au discours de la haine. Tout d'abord, je présenterai le débat théorique sur la relation entre la politique, la mémoire et l'éducation, encadrant ainsi les catégories qui guident les réflexions développées tout au long du texte. Dans un deuxième temps, je raconterai mon expérience ethnographique lors des élections présidentielles brésiliennes de 2018 et de dialogue avec Carlos, un jeune homme noir de la ville brésilienne de Foz do Iguaçu, bénéficiaire de l'aide éducative du gouvernement du Parti des travailleurs et électeur de Bolsonaro. Dans les considérations finales, j'identifierai le rôle de la mémoire sociale et des "inventaires de la mémoire" comme outils pour surmonter, à partir de l'éducation, la forclusion politique des sujets.

Mots-clés: autonomie; Brésil; éducation; extrême droite (politique); inégalité sociale; mémoire. 